\title{
Inter-population synchrony in adult survival and effects of climate and extreme weather in non-breeding areas of Atlantic puffins
}

\author{
T. K. Reiertsen ${ }^{1, *, \#, \text { K. Layton-Matthews }{ }^{1, \#}, \text { K. E. Erikstad }}{ }^{1,2}$, K. Hodges ${ }^{3}$, \\ M. Ballesteros ${ }^{1}$, T. Anker-Nilssen ${ }^{4}$, R. T. Barrett ${ }^{5}$, S. Benjaminsen ${ }^{1}$, M. Bogdanova $^{6}$, \\ S. Christensen-Dalsgaard ${ }^{4}$, F. Daunt ${ }^{6}$, N. Dehnhard ${ }^{4}$, M. P. Harris ${ }^{6}$, M. Langset $^{4}$, \\ S.-H. Lorentsen ${ }^{4}$, M. Newell ${ }^{6}$, V. S. Bråthen ${ }^{4}$, I. Støyle-Bringsvor ${ }^{7}$, G.-H. Systad ${ }^{8}$, S. Wanless ${ }^{6}$ \\ ${ }^{1}$ Norwegian Institute for Nature Research, FRAM Centre, 9296 Tromsø, Norway \\ ${ }^{2}$ Centre for Biodiversity Dynamics, Norwegian University of Science and Technology, 7491 Trondheim, Norway \\ ${ }^{3}$ Department of Meteorology, University of Reading, Reading RG6 6ET, UK \\ ${ }^{4}$ Norwegian Institute for Nature Research, 7485 Trondheim, Norway \\ ${ }^{5}$ Department of Natural Sciences, Tromsø University Museum, 9037 Tromsø, Norway \\ ${ }^{6}$ UK Centre for Ecology \& Hydrology, Bush Estate, Penicuik EH26 0QB, UK \\ ${ }^{7}$ Støyle 19, 6089 Sandshamn, Norway \\ ${ }^{8}$ Norwegian Institute for Nature Research, 5006 Bergen, Norway
}

\begin{abstract}
Seabirds are undergoing drastic declines globally and spend the non-breeding season at sea, making it challenging to study the drivers of their survival. Harsh weather and changes in climate conditions can have large impacts on seabird population dynamics through increased mortality. The intensity and persistence of extreme events are forecasted to increase with global warming. As shared conditions can induce population synchrony, multi-population studies of key demographic parameters are imperative to explore the influence of climate change. We used long-term mark-recapture data and position data to determine non-breeding stop-over areas of 5 Atlantic puffin (Fratercula arctica) populations over a latitudinal gradient in the Northeast Atlantic $\left(56^{\circ} 11^{\prime}-70^{\circ} 23^{\prime} \mathrm{N}\right)$. We investigated synchrony in adult survival in relation to shared stopover areas. We quantified effects of extreme extra-tropical cyclones (ETCs) specific to populations' stop-over areas and the North Atlantic Oscillation on adult survival. Populations with overlapping stop-over areas exhibited temporal synchrony in survival rates. Winter ETCs negatively influenced survival in 1 population, which was the one most exposed to extreme weather, but did not directly influence adult survival in the other 4 populations. Synchrony among populations with shared stop-over areas highlights the importance of these areas for adult survival, a key lifehistory rate. However, extreme weather was not identified as a driving factor for the majority of study populations. This suggests other factors in these areas, likely related to bottom-up trophic interactions, as environmental drivers of synchrony in the survival of Atlantic puffins.
\end{abstract}

KEY WORDS: Non-breeding distribution • Mark-recapture $\cdot$ Synchrony $\cdot$ North Atlantic Oscillation · Extreme weather $\cdot$ Extra-tropical cyclones $\cdot$ Seabirds $\cdot$ Fratercula arctica

\section{INTRODUCTION}

Seabirds are one of the most threatened groups of bird (Croxall et al. 2012). Many seabird species are currently on the IUCN Red List, with declining popu-

*Corresponding author: tone.reiertsen@nina.no

\#These authors contributed equally to this work

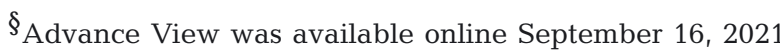

lation trends observed (BirdLife International 2018). Climate change impacts seabird populations via effects on survival and reproduction (e.g. Le Bohec et al. 2008, Hansen et al. 2021), and climate change and extreme weather are considered among the top 3

() The authors 2021. Open Access under Creative Commons by Attribution Licence. Use, distribution and reproduction are unrestricted. Authors and original publication must be credited. 
threats to seabirds globally (Dias et al. 2019). However, the role of climate during the non-breeding season in driving variation in survival and thus seabird population dynamics remains poorly understood. Quantifying population-level impacts requires an understanding of the drivers of temporal population fluctuations at large spatial scales (Jenouvrier et al. 2009, Descamps et al. 2021 in this Theme Section).

The sharing of a common environment by individuals from different populations can lead to synchronous fluctuations in demographic rates and - to some extent - also population growth rates because of e.g. shared weather effects (Grøtan et al. 2005, Koenig \& Liebhold 2016). Extinction risk tends to be greater in synchronously fluctuating populations, since a common environmental effect will have a bigger impact overall (Heino et al. 1997, Palmqvist \& Lundberg 1998). Large-scale climate patterns can induce synchrony in seabird survival and reproduction, both within a species across breeding colonies and across species within a colony, through bottom-up effects on prey availability (Frederiksen et al. 2005, LahozMonfort et al. 2011). Thus, climate change has the potential to alter population synchrony, via demographic effects. Furthermore, increasing temporal variability associated with climate change may alter patterns in population synchrony (Hansen et al. 2020). In this way, synchrony will likely play a key role in the larger-scale impacts of climate change (e.g. Defriez et al. 2016).

Large-scale climate indices such as the North Atlantic Oscillation (NAO) have been widely adopted to quantify (often indirect) effects of climate fluctuations. Such indirect effects occur through prey availability on adult survival and recruitment (Grosbois \& Thompson 2005, Harris et al. 2005, Sandvik et al. 2005), i.e. via altered abundance or shifts in spatial distribution (Sandvik et al. 2005, Peron et al. 2010, Lewison et al. 2012). Climate change has also affects seabirds directly, e.g. through increased mortality caused by more frequent storms and other extreme weather events (Frederiksen et al. 2008, Acker et al. 2021). Thus, understanding whether extreme events play a role in shaping population dynamics is imperative to understand current, and predict future, ecological consequences of climate change (Thomas et al. 2004, Post et al. 2009). While large-scale climate indices integrate multiple climate effects on demography over a large spatial scale, they are less good at capturing area-specific, and especially, extreme weather events. Consequently, evidence of localised, severe weather effects on demography remains scarce.
The North Atlantic boreal and low-Arctic coastal areas are highly productive and important foraging areas for seabirds (Newton 2003, Gaston 2004). Climate conditions in these areas are shown to influence seabirds inhabiting this region (Grosbois \& Thompson 2005, Sandvik et al. 2005). Furthermore, climate change may increase the persistence and intensity of storm activity in the North Atlantic (Ulbrich et al. 2009, Champion et al. 2011, Priestley et al. 2020), with potentially severe implications for seabird populations. Therefore, understanding the impacts of extreme weather in non-breeding areas on seabird populations is imperative (Frederiksen et al. 2008, Van de Pol et al. 2017). Extra-tropical cyclones (ETCs) are defined as cyclones occurring between 30 and $90^{\circ} \mathrm{N}$ or $\mathrm{S}$ in the northern and southern hemispheres, respectively. At northern latitudes, ETCs represent weather systems with anti-clockwise circulation centred around an area of low atmospheric pressure. They are a dominant feature of mid-latitudes and are associated with extreme winds, intense precipitation, and temperature fluctuations (Hoskins \& Hodges 2002, Ulbrich et al. 2009, Wang et al. 2013, Pinto \& Ludwig 2020). ETCs span a broad range of intensities, frequencies, and trajectories, and the complexity of ETC behaviour may, in part, explain the lack of understanding of their influence on marine seabird communities. Nevertheless, recent studies have attributed winter ETCs as drivers of temporal fluctuations in seabird survival (e.g. Guéry et al. 2019).

While single-population studies remain the norm in investigating the impacts of climate change in seabirds and other organisms, the importance of multipopulation studies is becoming increasingly apparent (Grosbois et al. 2009, Lahoz-Monfort et al. 2011). However, the number of multi-population studies remains limited (but see Frederiksen et al. 2008, Carroll et al. 2015, Descamps et al. 2021), and particularly the consistency of populations in their response to climate conditions (e.g. extreme weather) in the non-breeding season remains largely unexplored.

In long-lived species like seabirds, climate-induced changes in adult survival have the potential to strongly impact population trajectories (Lebreton \& Clobert 1991, Stearns 1992). The non-breeding-, and especially wintering-, period is a critical stage for seabird survival (Barbraud \& Weimerskirch 2005, Sandvik et al. 2005, Frederiksen et al. 2008). This period is also when ETCs are most extreme in the North Atlantic. The development of bird-borne tracking devices such as miniature light-level geolocators (GLS) has made it possible to study seabirds' migratory behaviour outside the breeding season 
(e.g. Phillips et al. 2004, Frederiksen et al. 2012, Fayet et al. 2017) and investigate how the environment in non-breeding areas affects adult survival (e.g. Reiertsen et al. 2014). Yet, few studies have done this in a multi-colony perspective (but see Guéry et al. 2019).

The Atlantic puffin is a highly abundant seabird, endemic to the colder parts of the North Atlantic. The species' global population size has declined markedly over the last 4 decades, and the species is listed as Vulnerable on the IUCN Red list (BirdLife International 2018). Puffins are long-lived (average life expectancy of $25 \mathrm{yr}$ ), mature late (5 yr), and have a single-egg clutch (Harris \& Wanless 1984). Longterm studies have been conducted on multiple populations for decades (Harris et al. 2005). More recent work indicates that regionally distinct breeding populations generally differ in their migratory route and behaviour, possibly due to competition for scarce winter resources (Fayet et al. 2017).

Here, we combined large-scale data from miniature year-round, light-based tracking devices ('geolocators' or 'GLS-loggers') for determining the nonbreeding distribution with long-term mark-recapture data, providing estimates of adult survival from 5 breeding populations of Atlantic puffins in the Northeast Atlantic (latitudinal range: $56^{\circ} 11^{\prime}-70^{\circ} 23^{\prime} \mathrm{N}$ ). Extreme weather is expected to be most intense during the winter period (Hoskins \& Hodges 2002), and this time-period is generally viewed as the most critical time-period for seabird survival (Sandvik et al. 2005, Frederiksen et al. 2008, Smith \& Gaston 2012). Therefore, we quantified whether large-scale climate variation (NAO) and local extreme weather conditions (extreme ETCs) in their winter stop-over areas (i.e. during the non-migratory period) contributed to temporal fluctuations in adult survival. We tested 2 main hypotheses: (1) Populations with a large degree of overlap in their stop-over distribution exhibit a high degree of temporal synchrony in adult survival, and (2) both NAO and extreme ETCs in population-specific stop-over areas negatively affect adult survival. We tested Hypothesis 1 by quantifying the overlap among populationspecific stop-over areas and the level of synchrony in adult survival among populations. We addressed Hypothesis 2 by testing the effect of NAO and ETCs both separately and in combination, allowing us to determine whether extreme weather, which is associated with a positive NAO, is the mechanism behind shared effects of NAO or whether it explains additional variation (i.e. pointing to alternative mechanisms).

\section{MATERIALS AND METHODS}

\subsection{Study species}

The Atlantic puffin is a medium sized seabird distributed largely in boreal areas on both sides of the North Atlantic. Each year, individuals breed in colonies on remote islands along the coast and lay a single egg in burrows or under boulders. Both sexes incubate and take part in chick rearing, so we considered there to be no gender-specific differences in capture or resighting probabilities (Harris \& Wanless 1984). Outside the breeding season, puffins spend the autumn and winter in the open sea, predominantly in the North Atlantic and Barents Sea (Fayet et al. 2017).

\subsection{Mark-recapture data}

We used mark-recapture data from 5 puffin populations spread along a latitudinal gradient in the Northeast Atlantic: Isle of May $\left(56^{\circ} 11^{\prime} \mathrm{N}, 2^{\circ} 34^{\prime} \mathrm{W}\right)$, Runde $\left(62^{\circ} 26^{\prime} \mathrm{N}, 5^{\circ} 52^{\prime} \mathrm{E}\right)$, Røst $\left(67^{\circ} 26^{\prime} \mathrm{N}, 1^{\circ} 52^{\prime} \mathrm{E}\right)$, Anda $\left(69^{\circ} 03^{\prime} \mathrm{N}, 15^{\circ} 10^{\prime} \mathrm{E}\right)$ and Hornøya $\left(70^{\circ} 23^{\prime} \mathrm{N}, 31^{\circ} 09^{\prime} \mathrm{E}\right)$ (Fig. 1A). Mark-recapture histories were available for 699 individuals at Isle of May (years 1984-2019), 394 individuals at Runde (2007-2019), 572 individuals at Røst (1990-2019), 527 individuals at Anda (20052019), and 952 individuals at Hornøya (1990-2019). Birds were caught and marked with either an individually coded colour ring or a unique combination of colour rings. In each subsequent year, resighting was conducted with visual searches for these birds predominantly in the areas where they had been ringed.

The encounter histories for each population were modelled within a Cormack-Jolly-Seber (CJS) framework. The fits of the datasets to a CJS reference model (Lebreton et al. 1992) were tested with a goodnessof-fit (GOF) test in the package U-CARE (Choquet et al. 2009). All datasets exhibited (positive) trap dependency i.e. the annual probability of resighting an individual depended on whether it was caught in the previous year (Table S1 in Supplement 1 at www.intres.com/articles/suppl/m676p219_supp.pdf).

\subsection{Colony core non-breeding areas}

Non-breeding distributions of puffins from the 5 populations were derived from tracking data using GLS deployed on birds in the years 2014-2019 (Supplement 2). We extracted GLS data from all years and for 2 non-migratory periods, autumn (August- 

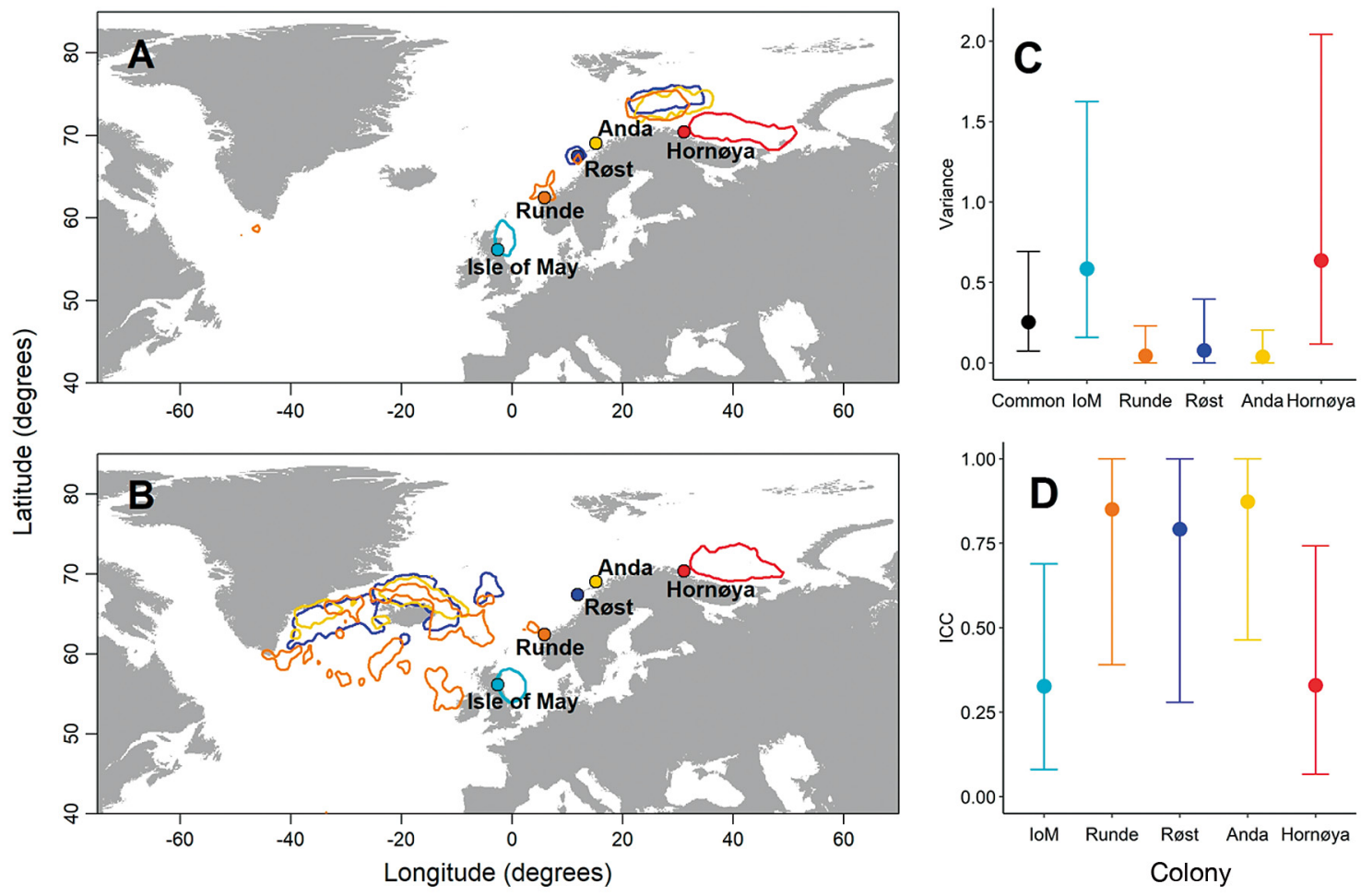

Fig. 1. (A,B) Breeding colonies (coloured points) of each Atlantic puffin population: Isle of May (IoM, turquoise), Runde (orange), Røst (blue), Anda (yellow), Hornøya (red). Contours represent non-breeding distributions (50\% kernel contours, see Section 2.3) of birds from each population in (A) autumn (August-September) and (B) winter (December-January). (C) Estimates of the temporal variation shared among colonies, i.e. synchronous variance ( $\hat{\sigma}_{\delta}^{2}$, 'Common') and variation not shared among colonies, i.e. asynchronous variance ( $\hat{\sigma}_{c o l}^{2}$, colonies). (D) Proportion of variation explained by the common variance term versus the colony-specific variance term (i.e. the inter-class correlation, ICC) for each population. Error bars: $95 \%$ credible intervals

September) and winter (December-January), i.e. when birds did not make long distance movements (Fig. S1 in Supplement 3). In total (i.e. across seasons and years), 240 individuals were retrieved with GLS from Hornøya colony, 300 individuals from Røst, 62 from Anda, 56 from Runde and 157 from Isle of May (Table S2 in Supplement 2).

Migratory time-periods were avoided in order to investigate the overlap in non-breeding distributions and the effects of winter climate conditions within a fixed area. Since GLS data only cover a subset of the years that mark-recapture data were available, we had to assume that individuals from each colony had relatively stable non-breeding distributions. This assumption was verified by testing for between-year consistency using the GLS data of puffins from Isle of May (2014-2018), Røst (2014-2018) and Hornøya (20122018) (Supplement 4). The $50 \%$ utilisation distributions representing the core area for puffins from each colony were created for each year. Between-year overlap in the distributions was calculated using Bhattacharyya's affinity (Fieberg \& Kochanny 2005). Between-year consistency could not be tested for Runde and Anda due to small annual sample sizes (Table S1 in Supplement 1).
For each population, we represented individuals' core non-breeding areas by producing utilisation distributions (i.e. $50 \%$ kernel density contours) using GLS data from years 2014-2019 (i.e. pooled across years [Fig. S5 in Supplement 5], assuming high withincolony consistency [Supplement 4]). Kernel density contours and pairwise population overlaps were calculated using the Arctic Polar Stereographic projection. For representation on the maps, the kernels were reprojected to latitude and longitude coordinates on the WGS84 reference ellipsoid. We calculated the proportion of overlap between each of the $50 \%$ kernels (i.e. autumn and winter kernels for each population) using the package adehabitatHR in $\mathrm{R} v$ v 3.6.3 (Calenge et al. 2009). Overlap was categorised as: no overlap $(<3 \%)$, small $(4-20 \%)$, medium $(21-50 \%)$, or high (51-100\%) degree of overlap.

\subsection{Synchrony in adult survival}

To test Hypothesis 1, we estimated the temporal synchrony in adult survival using the mark-recapture data for the years 2007-2019 (i.e. the period for 
which data were available for all populations) and compared the level of synchrony with the degree of overlap in the populations' autumn and winter utilisation distributions. We modelled temporal synchrony in survival among colonies as logit $\left(\phi_{\mathrm{col}, t} t\right)=\alpha_{\mathrm{col}}+\delta_{t}+$ $\varepsilon_{\text {col, }, t}$, where $\alpha_{\text {col }}$ is the colony-specific intercept, $d_{t}$ is a random term dependent on year $(t)$ but common to all colonies, and $\varepsilon_{\mathrm{col}, t}$ is a random term specific to both colony and year. Each random term was assumed to be independent and identically distributed and was drawn from a normal distribution (Grosbois et al. 2009). Using this model, we estimated the common year variance component $\left(\hat{\sigma}_{\delta}^{2}\right)$ and colony-specific year variance component $\left(\hat{\sigma}_{\mathrm{col}}^{2}\right)$ to calculate the intraclass correlation coefficient ICC $_{\mathrm{col}}$ (Lahoz-Monfort et al. 2011), which describes the proportion of variance in a colony that is synchronous with all other colonies $\left(\mathrm{ICC}_{\mathrm{col}}=\hat{\sigma}_{\delta}^{2} /\left[\hat{\sigma}_{\delta}^{2}+\hat{\sigma}_{\varepsilon_{\mathrm{col}}}^{2}\right]\right)$.

Trap dependence in recapture rates was accounted for by adding a 1 yr trap dependence structure (Grosbois et al. 2009, Lahoz-Monfort et al. 2011). Modelling of synchrony was performed in a Bayesian framework, with non-informative priors and Markov Chain Monte Carlo (MCMC) sampling. Models were run in $\mathrm{R}$ (version 3.6.3), using program NIMBLE (version 0.10.1, de Valpine et al. 2017). All estimates are shown as means with $95 \%$ Bayesian credible intervals (CRIs).

\subsection{Winter climate covariates}

The NAO is a dominant teleconnection pattern in the North Atlantic describing large-scale weather patterns (Stenseth et al. 2003). It reflects the distribution and intensity of ETCs in the North Atlantic, where a positive NAO is associated with a northward shift in cyclone activity and is more pronounced in winter (Hurrell et al. 2003). NAO is a commonly used proxy to measure the effects of climate conditions on seabirds in the North Atlantic (e.g. Stenseth et al. 2003, Durant et al. 2004, Sandvik et al. 2012, Hovinen et al. 2014). Monthly values were available from NOAA Climate Prediction Center (www.cpc.ncep. noaa.gov/data/teledoc/telecontents.shtml).

ETCs were tracked using the approach described in Guéry et al. (2019), Hoskins \& Hodges (2002), and Roberts et al. (2014), i.e. using a maximum vorticity approach based on $850 \mathrm{hPa}$ relative vorticity for tracking the ETCs and winds $10 \mathrm{~m}$ above the sea surface for assessing their impact. Only tracks lasting $>1 \mathrm{~d}$ and traveling $>1000 \mathrm{~km}$ were retained (i.e. synoptic scale storms between 1000 and $2500 \mathrm{~km}$ ), to remove short-lived or stationary systems. Therefore, cyclone tracks were produced using data from the ERA5 reanalysis from the European Centre for MediumRange Weather Forecasts (Hersbach et al. 2020) at a $3 \mathrm{~h}$ temporal resolution for the period 1979-2019. To calculate winter ETC activity experienced by puffins from each colony, we constructed ellipses that overlapped with each colony's core distribution. Each ellipse included $95 \%$ of the observations within the $50 \%$ GLS kernel (Fig. S5 in Supplement 5). Extraction of ETC variables was done by masking the surface wind speed data for each colony using ellipses defined by their major and minor axes, estimated from the kernel distributions (a schematic is shown in Guéry et al. 2019). Maximum wind speeds within $6^{\circ}$ radius (geodesic) of the cyclone centres were added to the tracks from the masked fields, i.e. only winds from the regions defined by the ellipses were included if they were within the $6^{\circ}$ radius of the ETC centre (Guéry et al. 2019). To measure extreme ETC activity, only cyclones reaching wind speeds above the 95th percentile were used to calculate the annual number of extreme ETCs in winter $\left(\mathrm{ETC}_{\text {win }}\right)$, reflecting local, extreme storm activity. Table S8 in Supplement 6 provides an overview of the wind speed and duration of the extreme ETCs in both the autumn and winter stop-over areas. However, since we were interested in the effect of the most extreme ETCs, we only used ETCs from the winter stop-over sites for all 5 populations. The maximum wind speed in autumn was $25.5 \mathrm{~m} \mathrm{~s}^{-1}$, while it reached $37.5 \mathrm{~m} \mathrm{~s}^{-1}$ in winter (Table S8).

\subsection{Winter climate effects on adult survival}

To test Hypothesis 2, we identified the bestapproximating model of survival for each population during the most critical time-period for survival (winter), including the winter NAO $\left(\mathrm{NAO}_{\text {win }}\right)$, a stationbased index describing the difference in the pressure-level between the Azores and Iceland for the months December, January, February, and March, and the number of extreme ETCs passing within populations' wintering areas $\left(\mathrm{ETC}_{\text {win }}\right)$.

We modelled the mark-recapture datasets using the program MARK (White \& Burnham 1999) via the RMark interface (Laake 2013). Trap-dependent resighting was included to distinguish between individuals resighted in the previous year from those that were not. Based on an initial analysis, a timeand trap-dependent model of resighting probabilities was the best fit for all colonies. We did not include an 
interaction between year and trap dependence, since this led to model overparameterization.

We constructed candidate model sets including a constant model (i.e. intercept-only) and a timedependent model (i.e. with a fixed categorical effect of year), models with $\mathrm{NAO}_{\text {win }}$ only, $\mathrm{ETC}_{\text {win }}$ only, and both $\mathrm{NAO}_{\text {win }}$ and $\mathrm{ETC}_{\text {win }}$ as additive effects. We ensured none of the covariates entered in the same model had a correlation coefficient $>0.5$ (Fig. S6 in Supplement 7 ). All covariates were scaled (mean $=0$, standard deviation $=1$ ). Candidate models were ranked using Akaike's Information Criterion corrected for small sample sizes (AICc, Burnham \& Anderson 2002), where the model with the lowest AICc was considered the best-fitting model for each population. In addition, we performed an analysis of deviance using the ANODEV function in the program MARK, to determine whether the covariate(s) explained a significant amount of deviance. The most parsimonious model was considered the one with the lowest AICc and where covariates explained a statistically significant amount of deviance.

\section{RESULTS}

\subsection{Atlantic puffins' non-breeding distribution}

The 5 populations of Atlantic puffins showed a distinct distributional pattern during the non-breeding season. In August and September, all populations were in the Barents Sea, except for individuals from Isle of May, which were distributed in northeast Scotland (Fig. S1A in Supplement 3). This pattern was highly consistent between years for individuals from Isle of May, Røst, and Hornøya (Supplement 4), indicating that these areas represent autumn stop-over areas.

In October and November, populations were more widely distributed, especially puffins from Røst and Anda, with a distribution stretching from the Barents Sea to waters around Iceland and east of Greenland (Fig. S1B). In December and January, individuals from Runde, Røst and Anda were distributed around Iceland, with those from Runde more to the south and those from Røst and Anda more to the north. Populations from Isle of May and Hornøya were distributed east of Scotland and in the southeastern Barents Sea, respectively, in December-January (Fig. S1C). All populations were highly consistent in their distributions among years in December-January, likely reflecting a winter stop-over period, while October-November was more likely a migratory period. In February, individuals from Runde, Røst, and Anda were distributed across the North Atlantic again, i.e. populations were migrating back towards their breeding colonies (Fig. S1D). In April, all populations were at the breeding colonies (Fig. S1E).

\subsection{Overlap in the non-breeding areas}

There was no overlap in the utilisation distributions of individuals from Isle of May and Hornøya with any populations in either season (Fig. 1A,B, Tables S3 \& S4 in Supplement 2). In autumn, puffins from Røst, Anda, and Runde showed a high degree of overlap in their core non-breeding areas in the Barents Sea (46-66\%). In winter, those from Røst and Anda continued to have a high degree of overlap (>50\%). In contrast, the core distribution of puffins from Runde had a medium degree of overlap with the core distribution of puffins from Røst and Anda (>20\%).

The core non-breeding distributions of Hornøya, Røst, and Isle of May exhibited a high degree of among-year consistency (75-98\% overlap), i.e. annual core distributions were similar in both autumn and winter. Annual 50\% utilisation distributions and an index of similarity in core distributions among years are shown in Supplement 4.

\subsection{Synchrony in adult survival}

Adult survival was higher for Isle of May (mean: 0.90; 95\% CRI: 0.85-0.94) and Røst (0.90; 0.87-0.93) than Hornøya $(0.85 ; 0.76-0.91)$, Anda $(0.84 ; 0.79-$ $0.88)$, and Runde $(0.85 ; 0.80-0.89)$. The proportion of synchronous variance in adult survival for each population, i.e. $\mathrm{ICC}_{\mathrm{col}}$ (Fig. 1C,D), was high for Røst $(0.79$; $0.28-1.00)$, Anda (0.87; 0.45-1.00), and Runde (0.82; $0.31-1.00)$. These 3 populations also had high overlap in autumn and medium overlap in winter distributions ( $>50 \%$ for Anda with Røst, and $20 \%$ for Runde with

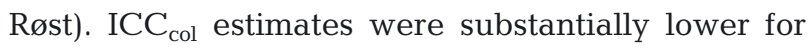
populations at Isle of May $(0.35 ; 0.09-0.72)$ and Hornøya $(0.32 ; 0.07-0.73)$, which did not overlap with other populations in either autumn or winter (Fig. 1D).

\subsection{Dynamics of extreme weather in non-breeding areas}

Puffins spending the winter south of Iceland (Runde) were most exposed to winter cyclone tracks (Fig. 2). Consequently, the number of extreme ETCs passing through this population's non-breeding area 
was greater overall (Fig. 2B). Birds from Isle of May and Hornøya remained closer to the mainland, east of the UK and Norway, respectively, where there were fewer extreme ETCs (Fig. 2A), and individuals were less exposed to ETCs overall (Fig. 2B).

\subsection{Climate effects on adult survival}

For populations from Isle of May, Anda, and Hornøya, the best-fitting model (besides the timedependent model) included effects of both $\mathrm{NAO}_{\text {win }}$ and the number of extreme ETC $_{\text {win }}$ (Table 1). Both covariates had a negative effect on survival for the Isle of May colony but a positive effect for the Anda and Hornøya colonies. However, in all 3 cases, the deviance explained by the 2 covariates was not significant (Table 2). The correlation between the $\mathrm{NAO}_{\text {win }}$ and $\mathrm{ETC}_{\text {win }}$ covariates for Hornøya and Isle of May were also close to 0.5 (-0.48 and 0.44, respectively, Fig. S6 in Supplement 7), indicating that both covariates may explain part of the same variation. The second best-fitting model for Isle of May and Hornøya included only ETC $_{\text {win }}($ Table 1), which explained a significant $(p<0.1)$ amount of deviance (Table 2). The second bestfitting model for Anda included a negative effect of $\mathrm{NAO}_{\text {win }}$ (Table 1), but this covariate did not explain a significant amount of deviance (Table 2).

The best-fitting model of survival for puffins from the Runde population showed a negative effect of $\mathrm{ETC}_{\text {win }}$ (Fig. 3), which was statistically significant ( $\mathrm{p}<0.01$, Table 2 ). The bestfitting model for Røst (besides the time-dependent model) also included a negative effect of ETC $_{\text {wini }}$ however, this variable did not explain significant deviance (Table 2).

Temporal variability in apparent adult survival rates differed among colonies (Fig. S7 in Supplement 8). A time-dependent model was a better fit than covariate models and the constant (i.e. intercept only) model for Isle of May, Røst, Hornøya, and Anda (Table 1). For puffins from Runde, covariate models outperformed the constant model, which in turn outperformed the timedependent model.

\section{DISCUSSION}

We combined long-term demographic and nonbreeding distribution data from 5 populations of a long-lived seabird, the Atlantic puffin, in the Northeast Atlantic. Populations with overlapping nonbreeding distributions (Fig. 1A,B) showed substantial temporal synchrony in survival, compared to those with no overlap (Fig. 1C,D). Only for the population most exposed to extreme weather (Runde, Fig. 2) did winter ETCs have a significant, negative effect on
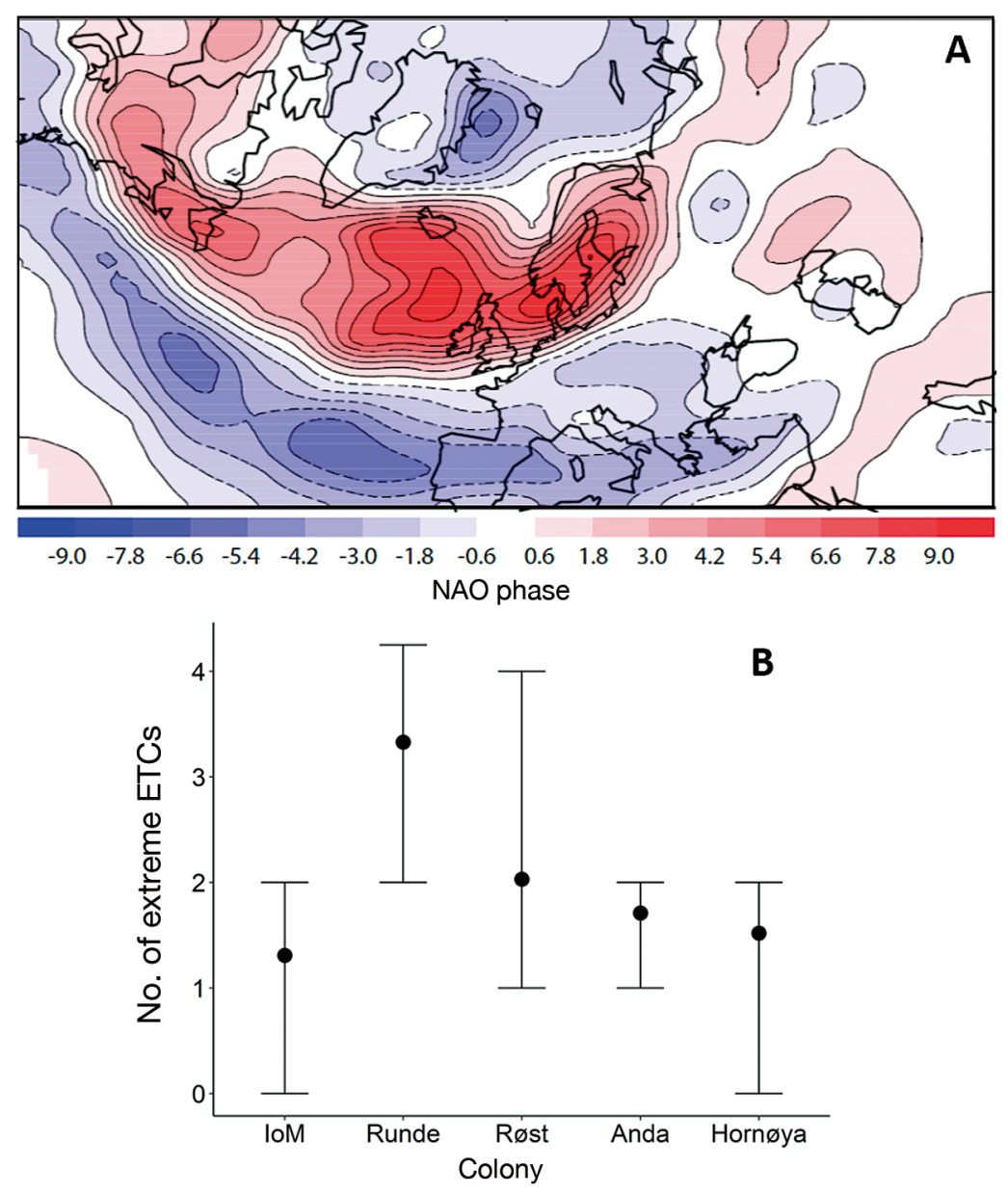

Fig. 2. (A) Differences in ETC track density (i.e. number of ETCs per season per unit area, with unit areas equivalent to a $5^{\circ}$ spherical cap) in winter (DecemberJanuary) for positive (red) and negative (blue) NAO phases. Increasingly red values correspond to more storms in a positive NAO, while increasingly blue values indicate more storms in a negative NAO (Hoskins \& Hodges 2002). In a positive NAO, the more frequent storm activity in the North Atlantic is focused south of Iceland. (B) Average (with $25^{\text {th }}$ and $75^{\text {th }}$ percentiles) number of extreme ETCs in winter passing through the core winter non-breeding area (represented by the $50 \%$ kernels in Fig. 1A,B) for puffin colonies 
Table 1. Candidate models of apparent adult survival for the 5 puffin colonies, showing the number of estimated parameters (Npar), AIC, $\triangle \mathrm{AICC}$ and model weight. Covariates were included describing the number of extreme extra-tropical cyclones in winter $\left(\mathrm{ETC}_{\mathrm{win}}\right)$ and winter North Atlantic Oscillation $\left(\mathrm{NAO}_{\text {win }}\right)$. The recapture model was fitted with a year and (1 yr) trap dependency effect in all competing models. (-) Not calculated (time-dependent model was the best-fitting model)

\begin{tabular}{|c|c|c|c|c|}
\hline Model & Npar & $\mathrm{AICc}$ & $\triangle \mathrm{AICc}$ & Weight \\
\hline \multicolumn{5}{|l|}{ Isle of May } \\
\hline Time & 70 & 6540.46 & - & - \\
\hline$-0.15(-0.27,-0.03) \mathrm{NAO}_{\text {win }}-0.15(-0.25,-0.04) \mathrm{ETC}_{\text {win }}$ & 39 & 6677.52 & 0 & 0.85 \\
\hline$-0.21(-0.30,-0.12) \mathrm{ETC}_{\text {win }}$ & 38 & 6681.79 & 4.27 & 0.10 \\
\hline$-0.22(-0.33,-0.12) \mathrm{NAO}_{\text {win }}$ & 38 & 6683.33 & 5.81 & 0.05 \\
\hline Constant & 37 & 6699.37 & 21.84 & 0 \\
\hline \multicolumn{5}{|l|}{ Runde } \\
\hline$-0.30(-0.52,-0.08) \mathrm{ETC}_{\text {win }}$ & 15 & 2820.39 & 0 & 0.54 \\
\hline$-0.24(-0.51,0.03) \mathrm{ETC}_{\text {win }}-0.10(-0.37,0.17) \mathrm{NAO}_{\text {win }}$ & 16 & 2821.91 & 1.52 & 0.25 \\
\hline$-0.23(-0.44,-0.01) \mathrm{NAO}_{\text {win }}$ & 15 & 2822.76 & 2.37 & 0.16 \\
\hline Constant & 14 & 2825.10 & 4.71 & 0.02 \\
\hline Time & 24 & 2834.01 & 13.62 & 0 \\
\hline \multicolumn{5}{|l|}{ Røst } \\
\hline Time & 58 & 5444.83 & - & - \\
\hline$-0.10(-0.21,0.01) \mathrm{ETC}_{\text {win }}$ & 32 & 5472.45 & 0 & 0.39 \\
\hline Constant & 31 & 5473.31 & 0.87 & 0.25 \\
\hline $0.07(-0.06,0.19) \mathrm{NAO}_{\text {win }}-0.11(-0.22,0.00) \mathrm{ETC}_{\text {win }}$ & 33 & 5473.39 & 0.95 & 0.24 \\
\hline $0.04(-0.08,0.17) \mathrm{NAO}_{\text {win }}$ & 32 & 5474.89 & 2.44 & 0.11 \\
\hline \multicolumn{5}{|l|}{ Anda } \\
\hline Time & 28 & 3196.55 & - & - \\
\hline$-0.17(-0.34,0.00) \mathrm{NAO}_{\text {win }}+0.14(-0.02,0.30) \mathrm{ETC}_{\text {win }}$ & 18 & 3208.57 & 0 & 0.41 \\
\hline$-0.13(-0.30,0.03) \mathrm{NAO}_{\text {win }}$ & 17 & 3209.72 & 1.15 & 0.23 \\
\hline Constant & 16 & 3210.19 & 1.62 & 0.18 \\
\hline $0.11(-0.05,0.26) \mathrm{ETC}_{\text {win }}$ & 17 & 3210.33 & 1.76 & 0.17 \\
\hline \multicolumn{5}{|l|}{ Hornøya } \\
\hline Time & 57 & 9323.83 & - & - \\
\hline $0.38(0.20,0.56) \mathrm{ETC}_{\text {win }}+0.15(0.02,0.28) \mathrm{NAO}_{\text {win }}$ & 33 & 9397.57 & 0 & 0.82 \\
\hline $0.27(0.13,0.41) \mathrm{ETC}_{\text {win }}$ & 32 & 9400.57 & 3.00 & 0.18 \\
\hline Constant & 31 & 9416.81 & 19.24 & 0.42 \\
\hline$-0.03(-0.16,0.09) \mathrm{NAO}_{\text {win }}$ & 32 & 9418.58 & 21.01 & 0.22 \\
\hline
\end{tabular}

adult survival (Fig. 3). Higher synchrony between populations with overlapping non-breeding areas supports shared non-breeding conditions as a common driver of variation in survival. Neither extreme ETCs nor (non-lagged) NAO in winter appear to be major climate-related drivers of Atlantic puffin survival; however, extreme ETCs influenced survival in the most exposed population wintering south of Iceland (with the caveat that the time series for this population were relatively short). This points to other variables, e.g. variation in prey availability associated with ocean conditions at winter or autumn stop-over areas or lagged effects (Harris et al. 2005), as a source of variation - and synchrony - in survival. Although we cannot discount effects of ETCs in the migratory period, it is unlikely that extreme weather acts as a common driver of survival since populations' distributions exhibited far less overlap during these timeperiods (Fig. S1B,D).

\subsection{Spatial synchrony in relation to non-breeding areas}

In migratory species, shared non-breeding grounds can lead to synchrony in population dynamics (Schaub et al. 2005, Reynolds et al. 2011). In some seabird species (e.g. black-legged kittiwake Rissa tridactyla), populations from many colonies share wintering areas (Frederiksen et al. 2012, Bogdanova et al. 2014), while puffin populations appear to be more segregated (Fayet et al. 2017). Thus, synchrony in seabird survival in non-breeding areas, and specifically wintering areas, has been observed in some species (e.g. common guillemots Uria aalge, Reynolds et al. 2011) but not others (e.g. little auk Alle alle, Descamps et al. 2021). In the present study, Atlantic puffins from 3 Norwegian Sea populations (Runde, Anda, and Røst) shared non-breeding areas (20-50\% overlap in their core distributions) in autumn (in the 
Table 2. The percentage deviance $\left(\mathrm{R}^{2}\right)$ of each model with covariates and corresponding $\mathrm{p}$-value for the populations Isle of May, Runde, Røst, Anda and Hornøya. The number of extreme extra-tropical cyclones in winter $\left(\mathrm{ETC}_{\text {win }}\right)$ and winter North Atlantic Oscillation $\left(\mathrm{NAO}_{\text {win }}\right)$ were included as covariates

\begin{tabular}{|c|c|c|}
\hline Model & $\mathrm{R}^{2}$ & $\mathrm{p}$ \\
\hline \multicolumn{3}{|l|}{ Isle of May } \\
\hline $\mathrm{ETC}_{\text {win }}$ & 8.67 & 0.09 \\
\hline $\mathrm{NAO}_{\text {win }}$ & 7.99 & 0.11 \\
\hline $\mathrm{ETC}_{\text {win }}+\mathrm{NAO}_{\text {win }}$ & 11.45 & 0.15 \\
\hline \multicolumn{3}{|l|}{ Runde } \\
\hline $\mathrm{ETC}_{\text {win }}$ & 57.61 & $<0.01$ \\
\hline $\mathrm{NAO}_{\text {win }}$ & 37.41 & 0.05 \\
\hline $\mathrm{ETC}_{\text {win }}+\mathrm{NAO}_{\text {win }}$ & 62.16 & 0.02 \\
\hline \multicolumn{3}{|l|}{ Røst } \\
\hline $\mathrm{ETC}_{\text {win }}$ & 3.46 & 0.34 \\
\hline $\mathrm{NAO}_{\text {win }}$ & 0.54 & 0.71 \\
\hline $\mathrm{ETC}_{\text {win }}+\mathrm{NAO}_{\text {win }}$ & 4.76 & 0.54 \\
\hline \multicolumn{3}{|l|}{ Anda } \\
\hline $\mathrm{ETC}_{\text {win }}$ & 4.95 & 0.47 \\
\hline $\mathrm{NAO}_{\text {win }}$ & 6.56 & 0.39 \\
\hline $\mathrm{ETC}_{\text {win }}+\mathrm{NAO}_{\text {win }}$ & 14.90 & 0.45 \\
\hline \multicolumn{3}{|l|}{ Hornøya } \\
\hline ETC $_{\text {win }}$ & 12.51 & 0.07 \\
\hline $\mathrm{NAO}_{\text {win }}$ & 0.18 & 0.83 \\
\hline $\mathrm{ETC}_{\text {win }}+\mathrm{NAO}_{\text {win }}$ & 15.96 & 0.12 \\
\hline
\end{tabular}

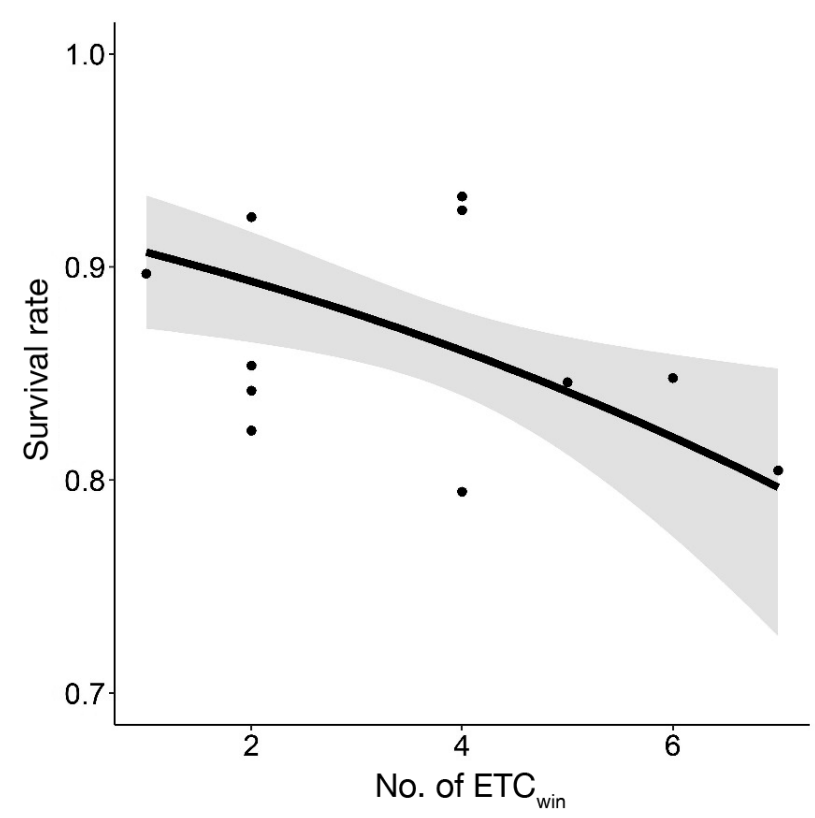

Fig. 3. Model prediction (black line) with $95 \%$ confidence interval (grey shading) of the effect of the number of extreme ETCs in winter $\left(\mathrm{ETC}_{\mathrm{win}}\right)$ on apparent adult survival of puffins from Runde colony. Points show estimates of annual survival based on a time-dependent model (i.e. with year fitted as a fixed effect), plotted against the corresponding $\mathrm{ETC}_{\text {win }}$ value for that year
Barents Sea) and winter (around Iceland and eastern Greenland). These populations also exhibited temporal synchrony in survival rates $\left(>0.75 \mathrm{ICC}_{\mathrm{col}}\right)$, pointing to environmental conditions during these non-migratory periods as a common driver of adult survival rates. Synchronous survival can have profound implications for seabird population dynamics, as separate breeding populations are collectively at risk from extrinsic (e.g. climatic, anthropogenic) drivers of mortality in non-breeding areas. As a consequence, highly synchronous populations may be at a greater risk of extinction overall (Heino et al. 1997, Palmqvist \& Lundberg 1998). This has implications for puffin populations sharing their non-breeding grounds, if climate change in these regions negatively affects their survival. However, in general, puffin populations do appear to segregate between regions (Fayet et al. 2017), thus regional differences would be expected.

\subsection{Winter climate and extreme ETCs}

The non-breeding period, and in particular winter, is critical for seabird survival as a consequence of environmental constraints such as shorter days (i.e. less time available for daylight foraging), harsher weather conditions and limited food availability (Frederiksen et al. 2008, Smith \& Gaston 2012). Extreme winter weather events affect population dynamics via survival (Frederiksen et al. 2008) and breeding success (Piatt et al. 2020) in long-lived seabirds and are considered the probable cause of seabird massmortality events or 'seabird wrecks' (Harris \& Wanless 1996).

Except for one population, population-specific variables describing winter extreme ETCs did not provide strong evidence that this was a main driver of variation in Atlantic puffin adult survival. Apart from individuals from Runde, neither local extreme ETC conditions nor unlagged winter NAO explained a substantial part of the temporal variation in survival. However, only 2 out of 8 non-breeding months were considered here. These variables may be more important in the other non-breeding months, although winter months are when storm activity appears to have the greatest effect on seabird survival (Frederiksen et al. 2008, Smith \& Gaston 2012). There was, however, evidence that individuals from Runde were negatively affected by extreme winter ETCs. Wintering individuals from Runde, Røst, and Anda were exposed to a relatively high frequency of extreme ETCs (our Fig. 2, Hoskins \& Hodges 2002). Puffins 
from Runde, which were distributed south of Iceland in winter, were exposed to the highest frequency of extreme winter ETCs (Fig. 2B). Individuals from Isle of May and Hornøya remained closer to their breeding colonies and were more sheltered from westerly cyclones. The mechanism behind potential negative effects of extreme storms on survival is probably starvation, due to inaccessibility of prey and/or the seabirds' inability to feed during cyclones, rather than increased energy requirements during cyclonic conditions (Clairbaux et al. 2021b). However, the lack of cross-population generality of this negative effect may reflect the resilience of these seabirds to poor at-sea conditions (e.g. stormy conditions) or the difference in winter locations of puffins from the other populations. Consequently, our measure of extreme ETCs does not capture the conditions leading to mortality events well, pointing to other external factors, e.g. other weather factors besides ETCs, oceanographic conditions, or lagged effects of climate on prey availability (Harris et al. 2005).

Neither extreme weather nor (non-lagged) largescale climate conditions (NAO) in winter explained the observed temporal synchrony in adult survival. Climate fluctuations can propagate through a food web via trophic interactions, causing synchronous population fluctuations at large spatial scales (Grøtan et al. 2005, Haynes et al. 2009). Fish-prey abundance is under climate control and influences the breeding success (Frederiksen et al. 2006, Cury et al. 2011, Olin et al. 2020) and survival (Reynolds et al. 2011) of seabirds. Consequently, the observed synchrony in puffin survival may arise from large scale, climateinduced fluctuations in prey availability. For instance, Lahoz-Monfort et al. (2011) found that sea surface temperature, which is associated with prey distributions, explained part of the temporal correlation in survival in 3 North Atlantic auk species. Existing synchrony may also be exacerbated by climate change, as effects of ocean warming alter nutrient availability and thus the marine food web (Sheppard et al. 2019). The fact that Isle of May and Hornøya populations exhibited a lower degree of synchrony and that individuals from these populations forage in different marine systems (i.e. with different trophic interactions) adds further evidence to indirect climate effects via prey as a main driver of synchrony.

Despite being a commonly used proxy, winter NAO did not explain substantial variation in survival in any of the puffin populations. Previously documented (often lagged) effects of large-scale indices on seabird survival, chiefly NAO, have been explained by strong correlations with ocean surface temperature that, in turn, influences survival via prey distributions (Reid et al. 1998, Leterme et al. 2005, Sandvik et al. 2008, Clairbaux et al. 2021a). The NAO, which influences e.g. wind speed and direction, induces changes in vertical ocean mixing, which in turn may affect prey species both within the same year but also have lagged effects in future years (Hurrell et al. 2003). Therefore, we cannot rule out that large-scale climate variation influences puffin survival indirectly through lagged effects.

Inter-population competition may be an important driver of differences in populations' migratory behaviour (Fayet et al. 2017). Larger populations or those with poorer local winter conditions close to their breeding grounds may migrate farther to find more productive areas. Puffins from Runde, Røst, and Anda made far longer migrations than those from Isle of May and Hornøya. Moreover, their wintering areas were exposed to more intense ETCs, potentially making these populations vulnerable to increases in the intensity and persistence of ETCs predicted in association with global warming (Ulbrich et al. 2009, Champion et al. 2011).

A lack of multi-year data on seabirds' non-breeding distributions and demography, as well as the inherent rarity of extreme events, makes quantifying the population-level effects of such events extremely challenging (Harris \& Wanless 1996, Anker-Nilssen et al. 2017). Nevertheless, developments in largescale tracking data and establishment of long-term GLS-monitoring programmes can shed light on the location and behaviour of seabirds during this previously unobservable period (Frederiksen et al. 2012, Fort et al. 2013, Fauchald et al. 2019, Clairbaux et al. 2021a), making it possible to study climate effects in the non-breeding season in more detail (Reiertsen et al. 2014, Descamps et al. 2021). Our study is, to our knowledge, one of the few multi-colony studies to quantify the demographic effects of climate variables specific to seabird non-breeding areas. That puffins consistently use the same non-breeding habitat is important in order to document the relationship between environmental conditions and seabird demography when, as here, distributional data do not span as many years as the demographic data. However, recent studies suggest that foraging locations of nonbreeding Atlantic puffins are consistent across years (Guilford et al. 2011, Fayet et al. 2017), and the data available suggest that in years when conditions are less favourable, puffins feed at lower trophic levels rather than moving to a new non-breeding area ( $\mathrm{St}$ John Glew et al. 2019). These studies, in addition to our results, suggest that puffins are consistent in 
their use of stop-over areas during the non-breeding season. However, little is known about finer-scale movement and foraging behaviour, e.g. in response to extreme weather. Our among-year consistency results from the GLS-data from Isle of May, Hornøya, and Røst (for the years 2014-2018, which do not cover all years of mark-recapture data) support consistent non-breeding habitat use in Atlantic puffins, since among-year overlap in utilisation distributions was extremely high (generally >0.9, Supplement 4).

\section{CONCLUSIONS}

Our study has shown that Atlantic puffin populations sharing non-breeding areas exhibit greater synchrony in adult survival compared to populations that do not share non-breeding areas. This provides evidence that climate conditions in non-breeding habitats act, to some extent, as a common driver of Atlantic puffin survival. Climate change is expected to alter patterns of synchrony (Hansen et al. 2020). For Atlantic puffins and other seabird species, this could occur through e.g. large-scale shifts in prey distributions or more persistent and intense ETCs. The potential importance of changes in synchrony for seabird populations emphasises the need to quantify the extent to which seabirds share non-breeding distributions (e.g. Frederiksen et al. 2012, Fayet et al. 2017) and the climate factors driving synchrony in seabird population dynamics in such a threatened and declining species as the Atlantic puffin (BirdLife International 2018). We have illustrated the value of tracking data to produce covariates describing climate conditions specific to seabird's non-breeding distributions, rather than relying on large-scale climate indices, which cover a multitude of factors but do not bring us much closer to understanding the mechanisms behind climate-driven mortality (Harris et al. 2015). Although we found little evidence of ETCs in wintering areas as a common driver of adult survival, populations most exposed to extreme storms may experience negative effects. The forecasted increase in ETC intensity and persistence with climate change may cause seabirds to suffer from prolonged periods without food access, i.e. leading to more pronounced negative effects. An increased frequency of extreme weather could exacerbate negative effects of food shortages caused by climate-change-induced shifts in prey availability (i.e. abundance and distribution, Defriez et al. 2016, Sheppard et al. 2019). Further work should focus on quantifying the trophic pathways from abiotic con- ditions to these marine top predators outside the breeding season.

Acknowledgements. We thank the many people who have contributed to fieldwork of the long-term mark-recapture data of Atlantic puffins, the Norwegian Ringing Centre, the Norwegian Coastal Administration for permission to use the lighthouse as base for fieldwork on Hornøya and Anda, SEAPOP (www.seapop.no/en) and its preceding monitoring activities for funding, including the Norwegian Research Council grant number 192141, SEATRACK for coordinating the GLS logging across all the sites, the Norwegian Environment Agency for financing the monitoring of puffin survival rates in Norway, the Natural Environment Research Council (Award number NE/R016429/1 as part of the UK-SCaPE programme delivering National Capability), and the Joint Nature Conservation Committee for funding. We also thank 3 anonymous reviewers for constructive comments that substantially improved the manuscript.

\section{LITERATURE CITED}

Acker P, Daunt F, Wanless S, Burthe SJ and others (2021) Strong survival selection on seasonal migration versus residence induced by extreme climatic events. J Anim Ecol 90:796-808

Anker-Nilssen T, Harris MP, Kleven O, Langset M (2017) Status, origin, and population level impacts of Atlantic Puffins killed in a mass mortality event in southwest Norway early 2016. Seabird 30:1-14

Barbraud C, Weimerskirch H (2005) Environmental conditions and breeding experience affect costs of reproduction in blue petrels. Ecology 86:682-692

BirdLife International (2018) State of the world's birds: taking the pulse of the planet. BirdLife International, Cambridge

* Bogdanova MI, Wanless S, Harris MP, Lindström J and others (2014) Among-year and within-population variation in foraging distribution of European shags Phalacrocorax aristotelis over two decades: implications for marine spatial planning. Biol Conserv 170:292-299

Burnham KP, Anderson DR (2002) Model selection and multimodel inference: a practical information-theoretic approach. Springer, New York, NY

Calenge C, Dray S, Royer-Carenzi M (2009) The concept of animals' trajectories from a data analysis perspective. Ecol Inform 4:34-41

* Carroll MJ, Butler A, Owen E, Ewing SR and others (2015) Effects of sea temperature and stratification changes on seabird breeding success. Clim Res 66:75-89

* Champion AJ, Hodges KI, Bengtsson LO, Keenlyside NS, Esch M (2011) Impact of increasing resolution and a warmer climate on extreme weather from Northern Hemisphere extratropical cyclones. Tellus, Ser A, Dyn Meterol Oceanogr 63:893-906

Choquet R, Lebreton JD, Gimenez O, Reboulet AM, Pradel R (2009) U-CARE: utilities for performing goodness of fit tests and manipulating CApture-REcapture data. Ecography 32:1071-1074

Clairbaux M, Cheung WWL, Mathewson P, Porter W and others (2021a) Meeting Paris agreement objectives will temper seabird winter distribution shifts in the North Atlantic Ocean. Glob Change Biol 27:1457-1469 
Clairbaux M, Mathewson P, Porter W, Fort J and others (2021b) North Atlantic winter cyclones starve seabirds. Curr Biol 31(17):P3964-3971.E3

* Croxall JP, Butchart SHM, Lascelles B, Stattersfield AJ, Sullivan B, Symes A, Taylor P (2012) Seabird conservation status, threats and priority actions: a global assessment. Bird Conserv Int 22:1-34

Cury PM, Boyd IL, Bonhommeau S, Anker-Nilssen T and others (2011) Global seabird response to forage fish depletion - one-third for the birds. Science 334:1703-1706

* de Valpine P, Turek D, Paciorek CJ, Anderson-Bergman C, Temple Lang D, Bodik R (2017) Programming with models: writing statistical algorithms for general model structures with NIMBLE. J Comput Graph Stat 26:403-413

Defriez EJ, Sheppard LW, Reid PC, Reuman DC (2016) Climate change-related regime shifts have altered spatial synchrony of plankton dynamics in the North Sea. Glob Change Biol 22:2069-2080

Descamps S, Merkel B, Strøm H, Choquet R and others (2021) Sharing wintering grounds does not synchronize annual survival in a high Arctic seabird, the little auk. Mar Ecol Prog Ser 676:233-242

Dias MP, Martin R, Pearmain EJ, Burfield IJ and others (2019) Threats to seabirds: a global assessment. Biol Conserv 237:525-537

Wurant JM, Anker-Nilssen T, Hjermann DØ, Stenseth NC (2004) Regime shifts in the breeding of an Atlantic puffin population. Ecol Lett 7:388-394

Fauchald P, Tarroux A, Bråthen VS, Descamps S and others (2019) Arctic-breeding seabirds' hotspots in space and time - a methodological framework for year-round modelling of environmental niche and abundance using lightlogger data. NINA Report 1657. Norwegian Institute for Nature Research (NINA), Tromsø. http://hdl.handle.net/ 11250/2595504

Fayet AL, Freeman R, Anker-Nilssen T, Diamond A and others (2017) Ocean-wide drivers of migration strategies and their influence on population breeding performance in a declining seabird. Curr Biol 27:3871-3878

*Fieberg J, Kochanny CO (2005) Quantifying home-range overlap: the importance of the utilization distribution. J Wildl Manag 69:1346-1359

Fort J, Moe B, Strøm H, Grémillet D and others (2013) Multicolony tracking reveals potential threats to little auks wintering in the North Atlantic from marine pollution and shrinking sea ice cover. Divers Distrib 19: 1322-1332

Frederiksen M, Wright PJ, Harris MP, Mavor RA and others (2005) Regional patterns of kittiwake Rissa tridactyla breeding success are related to variability in sandeel recruitment. Mar Ecol Prog Ser 300:201-211

Frederiksen M, Edwards M, Richardson AJ, Halliday NC, Wanless S (2006) From plankton to top predators: bottom-up control of a marine food web across four trophic levels. J Anim Ecol 75:1259-1268

Frederiksen M, Daunt F, Harris MP, Wanless S (2008) The demographic impact of extreme events: stochastic weather drives survival and population dynamics in a long-lived seabird. J Anim Ecol 77:1020-1029

*Frederiksen M, Moe B, Daunt F, Phillips RA, and others (2012) Multicolony tracking reveals the winter distribution of a pelagic seabird on an ocean basin scale. Divers Distrib 18:530-542

Gaston AJ (2004) Seabirds: a natural history. Yale University Press, Cumberland, RI
Grosbois V, Thompson PM (2005) North Atlantic climate variation influences survival in adult fulmars. Oikos 109: 273-290

Grosbois V, Harris MP, Anker-Nilssen T, McCleery RH, Shaw DN, Morgan BJT, Gimenez O (2009) Modeling survival at multi-population scales using mark-recapture data. Ecology 90:2922-2932

Grøtan V, Sæther BE, Engen S, Solberg EJ and others (2005) Climate causes large-scale spatial synchrony in population fluctuations of a temperate herbivore. Ecology 86: 1472-1482

* Guéry L, Descamps S, Hodges KI, Pradel R and others (2019) Winter extratropical cyclone influence on seabird survival: variation between and within common eider Somateria mollissima populations. Mar Ecol Prog Ser 627:155-170

* Guilford T, Freeman R, Boyle D, Dean B, Kirk H, Phillips R, Perrins C (2011) A dispersive migration in the Atlantic puffin and its implications for migratory navigation. PLOS ONE 6:e21336

*Hansen BB, Grøtan V, Herfindal I, Lee AM (2020) The Moran effect revisited: spatial population synchrony under global warming. Ecography 43:1591-1602

*Hansen ES, Sandvik H, Erikstad KE, Yoccoz NG and others (2021) Centennial relationships between ocean temperature and Atlantic puffin production reveal shifting decennial trends. Glob Change Biol 27:3753-3764

Harris MP, Wanless S (1984) The puffin. T \& AD Poyser, Calton

Karris MP, Wanless S (1996) Differential responses of guillemot Uria aalge and shag Phalacrocorax aristotelis to a late winter wreck. Bird Study 43:220-230

* Harris MP, Anker-Nilssen T, McCleery RH, Erikstad KE, Shaw DN, Grosbois V (2005) Effect of wintering area and climate on the survival of adult Atlantic puffins Fratercula arctica in the eastern Atlantic. Mar Ecol Prog Ser 297:283-296

* Harris MP, Leopold MF, Jensen JK, Meesters EH, Wanless S (2015) The winter diet of the Atlantic puffin Fratercula arctica around the Faroe Islands. Ibis 157:468-479

*Haynes KJ, Liebhold AM, Fearer TM, Wang G, Norman GW, Johnson DM (2009) Spatial synchrony propagates through a forest food web via consumer-resource interactions. Ecology 90:2974-2983

*Heino M, Kaitala V, Ranta E, Lindström J (1997) Synchronous dynamics and rates of extinction in spatially structured populations. Proc R Soc Lond 264:481-486 [Biol]

* Hersbach H, Bell B, Berrisford P, Hirahara S and others (2020) The ERA5 global reanalysis. Q J R Meteorol Soc 146:1999-2049

*Hoskins BJ, Hodges KI (2002) New perspectives on the Northern Hemisphere winter storm tracks. J Atmos Sci 59:1041-1061

* Hovinen JEH, Welcker J, Descamps S, Strøm H, Jerstad K, Berge J, Steen H (2014) Climate warming decreases the survival of the little auk (Alle alle), a high Arctic avian predator. Ecol Evol 4:3127-3138

*Hurrell JW, Kushnir Y, Ottersen G, Visbeck M (eds) (2003) An overview of the North Atlantic oscillation. In: The North Atlantic Oscillation: climatic significance and environmental impact. Geophys Monogr Ser 134:1-35

Jenouvrier S, Caswell H, Barbraud C, Holland M, Strœve J, Weimerskirch H (2009) Demographic models and IPCC climate projections predict the decline of an emperor penguin population. Proc Natl Acad Sci USA 106: 1844-1847 
Koenig WD, Liebhold AM (2016) Temporally increasing spatial synchrony of North American temperature and bird populations. Nat Clim Chang 6:614-617

Laake JL (2013) RMark: an R interface for analysis ofcapture-recapture data with MARK. AFSC Processed Report 2013-01. Alaska Fisheries Science Center, National Marine Fisheries Service, NOAA, Seattle, WA. https:// apps-afsc.fisheries.noaa.gov/Publications/ProcRpt/PR2013 -01.pdf

Lahoz-Monfort JJ, Morgan BJT, Harris MP, Wanless S, Wanless S, Freeman SN (2011) A capture-recapture model for exploring multi-species synchrony in survival. Methods Ecol Evol 2:116-124

* Le Bohec C, Durant JM, Gauthier-Clerc M, Stenseth NC and others (2008) King penguin population threatened by Southern Ocean warming. Proc Natl Acad Sci USA 105: 2493-2497

Lebreton JD, Clobert J (1991) Bird population dynamics, management, and conservation: the role of mathematical modelling. In: Perrins CM, Lebreton JD, Hirons GJM (eds) Bird population studies: relevance to conservation and management. Oxford University Press, Oxford, p 105-125

Lebreton JD, Burnham KP, Clobert J, Anderson DR (1992) Modeling survival and testing biological hypotheses using marked animals: a unified approach with case studies. Ecol Monogr 62:67-118

* Leterme SC, Edwards M, Seuront L, Attrill MJ, Reid PC, John AWG (2005) Decadal basin-scale changes in diatoms, dinoflagellates, and phytoplankton color across the North Atlantic. Limnol Oceanogr 50:1244-1253

Lewison R, Oro D, Godley BJ, Underhill L and others (2012) Research priorities for seabirds: improving conservation and management in the 21st century. Endang Species Res 17:93-121

Newton I (2003) Speciation and biogeography of birds. Academic Press, Amsterdam

Olin AB, Banas NS, Wright PJ, Heath MR, Nager RG (2020) Spatial synchrony of breeding success in the blacklegged kittiwake Rissa tridactyla reflects the spatial dynamics of its sandeel prey. Mar Ecol Prog Ser 638: $177-190$

Palmqvist E, Lundberg P (1998) Population extinctions in correlated environments. Oikos 83:359-367

* Peron C, Authier M, Barbraud C, Delord K, Besson D, Weimerskirch $H$ (2010) Interdecadal changes in at-sea distribution and abundance of subantarctic seabirds along a latitudinal gradient in the Southern Indian Ocean. Glob Change Biol 16:1895-1909

Phillips RA, Silk JRD, Croxall JP, Afanasyev V, Briggs DR (2004) Accuracy of geolocation estimates for flying seabirds. Mar Ecol Prog Ser 266:265-272

* Piatt JF, Parrish JK, Renner HM, Schoen SK and others (2020) Extreme mortality and reproductive failure of common murres resulting from the northeast Pacific marine heatwave of 2014-2016. PLOS ONE 15:e0226087

* Pinto JG, Ludwig P (2020) Extratropical cyclones over the North Atlantic and western Europe during the Last Glacial Maximum and implications for proxy interpretation. Clim Past 16:611-626

* Post E, Forchhammer MC, Bret-Harte MS, Callaghan TV and others (2009) Ecological dynamics across the Arctic associated with recent climate change. Science 325: 1355-1358

Priestley MDK, Ackerley D, Catto JL, Hodges KI, McDonald RE, Lee RW (2020) An overview of the extratropical storm tracks in CMIP6 historical simulations. J Clim 33: 6315-6343

* Reid PC, Edwards M, Hunt HG, Warner AJ (1998) Phytoplankton change in the North Atlantic. Nature 391:546

Reiertsen TK, Erikstad KE, Anker-Nilssen T, Barrett RT and others (2014) Prey density in non-breeding areas affects adult survival of black-legged kittiwakes Rissa tridactyla. Mar Ecol Prog Ser 509:289-302

* Reynolds TJ, Harris MP, King R, Swann RL, Jardine DC, Frederiksen M, Wanless S (2011) Among-colony synchrony in the survival of Common Guillemots Uria aalge reflects shared wintering areas. Ibis 153:818-831

* Roberts JF, Champion AJ, Dawkins LC, Hodges KI and others (2014) The XWS open access catalogue of extreme European windstorms from 1979 to 2012. Nat Hazards Earth Syst Sci 14:2487-2501

* Sandvik H, Erikstad KE, Barrett RT, Yoccoz NG (2005) The effect of climate on adult survival in five species of North Atlantic seabirds. J Anim Ecol 74:817-831

* Sandvik H, Coulson T, Sæther BE (2008) A latitudinal gradient in climate effects on seabird demography: results from interspecific analyses. Glob Change Biol 14: 703-713

Sandvik H, Erikstad KE, Sæther BE (2012) Climate affects seabird population dynamics both via reproduction and adult survival. Mar Ecol Prog Ser 454:273-284

Schaub M, Kania W, Köppen U (2005) Variation of primary production during winter induces synchrony in survival rates in migratory white storks Ciconia ciconia. J Anim Ecol 74:656-666

Sheppard LW, Defriez EJ, Reid PC, Reuman DC (2019) Synchrony is more than its top-down and climatic parts: interacting Moran effects on phytoplankton in British seas. PLOS Comput Biol 15:e1006744

* Smith PA, Gaston AJ (2012) Environmental variation and the demography and diet of thick-billed murres. Mar Ecol Prog Ser 454:237-249

* St John Glew K, Wanless S, Harris MP, Daunt F and others (2019) Sympatric Atlantic puffins and razorbills show contrasting responses to adverse marine conditions during winter foraging within the North Sea. Mov Ecol 7:33

Stearns SC (1992) The evolution of life histories. Oxford University Press, Oxford

Stenseth NC, Ottersen G, Hurrell JW, Mysterud A and others (2003) Studying climate effects on ecology through the use of climate indices: the North Atlantic Oscillation, El Nino Southern Oscillation and beyond. Proc R Soc B 270:2087-2096

Thomas CD, Cameron A, Green RE, Bakkenes M and others (2004) Extinction risk from climate change. Nature 427: 145-148

Ulbrich U, Leckebusch GC, Pinto JG (2009) Extra-tropical cyclones in the present and future climate: a review. Theor Appl Climatol 96:117-131

* van de Pol M, Jenouvrier S, Cornelissen JHC, Visser ME (2017) Behavioural, ecological and evolutionary responses to extreme climatic events: challenges and directions. Philos Trans R Soc Lond B 372:20160134

Wang XL, Feng Y, Compo GP, Swail VR, Zwiers FW, Allan RJ, Sardeshmukh PD (2013) Trends and low frequency variability of extra-tropical cyclone activity in the ensemble of twentieth century reanalysis. Clim Dyn 40:2775-2800

*White GC, Burnham KP (1999) Program MARK: survival estimation from populations of marked animals. Bird Study 46:S120-S139 